\title{
LUGAR DE FALA, POLÍTICA IDENTITÁRIA E SEUS REFLEXOS NA PRÁXIS DA ESQUERDA
}

\author{
LUGAR DE DISCURSO, POLÍTICA DE IDENTIDAD Y SUS REFLEXIONES EN LA \\ PRAXIS DE LA IZQUIERDA
}

\author{
PLACE OF SPEECH, IDENTITY POLITICS AND ITS REFLECTIONS IN \\ LEFTIST PRAXIS
}

Lays Bárbara Vieira MORAIS ${ }^{1}$

RESUMO: Visa-se pensar o argumento político-filosófico do 'lugar de fala' e entender quais os desdobramentos dessa categoria. Pergunta-se de que maneira o conceito diagnostica e impacta a representação social na política moderna; quem são as subjetividades que estão ali; e como o "lugar de fala" impacta na ação e na política da Esquerda. Conclui-se que, o que pretendia ser uma estratégia revolucionária para derrubar opressões entrecruzadas, acabou por adquirir uma tendência cada vez maior a um individualismo por via obliqua, e afasta-se cada vez mais a ideia de um "nós" em um contexto em que a Esquerda passou a aceitar a democracia liberal e o capitalismo como horizonte último.

PALAVRAS-CHAVE: Política identitária. Lugar de fala. Esquerda. Neoliberalismo.

RESUMEN: El objetivo es pensar en el argumento político-filosófico del 'lugar de discurso' y comprender cuáles son los desarrollos en esta categoría. Preguntamos cómo el concepto diagnostica e impacta la representación social en la política moderna; Quiénes son las subjetividades que están allí y cómo el "lugar de discurso" impacta la acción y la política de la izquierda. Llegamos a la conclusión de que, lo que pretendía ser una estrategia revolucionaria para derrocar las opresiones entrelazadas, terminó adquiriendo una tendencia cada vez mayor hacia un individualismo a través de una forma oblicua, eliminando cada vez más la idea de un "nosotros" en un contexto donde pasa la izquierda aceptar la democracia liberal y el capitalismo como el horizonte final.

PALABRAS CLAVE: Política de identidad. Lugar de discurso. Izquierda. Neoliberalismo.

ABSTRACT: The objective here is to think about the political-philosophical argument of the 'place of speech' and understand what the developments in this category are. We asked, how the concept diagnoses and impacts social representation in modern politics; who are the subjectivities that are there; and how the "place of speech" impacts action and politics of the leftist. We conclude that, what was intended to be a revolutionary strategy to overthrow interlocking oppressions, ended up acquiring a growing trend towards an individualism, the

${ }^{1}$ Instituto Federal de Goiás (IFG), Goiânia - GO - Brasil. Professora Substituta no Departamento de Ciências Sociais. Mestre em Ciência Política e em Sociologia (UFG). ORCID: https://orcid.org/0000-0002-7325-9502. Email: lahbvm@gamil.com 
idea of an "us" is increasingly removed in a context where the leftist came to accept liberal democracy and capitalism as the ultimate horizon.

KEYWORDS: Identity politics. Place of speech. Leftist. Neoliberalism.

\section{Introdução}

Para iniciarmos essa discussão, é preciso estabelecer o que entendemos como identidade e o que entendemos como esquerda. Adotamos a concepção de Haider (2019), em que "identidade" é o que ele chama de fenômeno real, correspondendo ao modo como o Estado nos divide em sujeitos individuais (em indivíduos). Aqui, além disso, a identidade também é o modo como formamos nossa individualidade em resposta a um enorme leque de relações sociais. Ou seja, ela não deve ser encarada como uma abstração (leitura e emprego muito comuns da categoria) que não nos diz nada sobre as relações sociais especificas que a constituíram. Por outro lado, no que se refere a categoria "esquerda", esta, tanto no Brasil como no mundo (e aqui também é importante as especificidades sócio-históricas e políticas de cada local), não é um grupo homogêneo. Pelo contrário, há várias "esquerdas", com diferenças e divergências entre si (ex.: socialdemocracia, esquerda moderada, esquerda liberal, esquerda radical, etc.), por isso a noção é melhor pautada se encarada pela teoria e prática adotadas, compondo o que se chama de "campo da esquerda". Assim, às "esquerda" aqui funciona como um termo guarda-chuva para esses grupos e para se referir aos vários desses grupos que abordam pautas progressistas, associadas (no século XX) à lutas por direitos humanos e sociais, se opondo ao conservadorismo, buscando avanços sociais e políticos, uma democracia mais plural, valorização da diferença (lembrando que a categoria também passa por variações históricas), etc. $^{3}$

Dito isso, podemos trazer duas coisas que vem marcando forte presença na militância brasileira nos últimos anos: primeiro, termos como lugar de fala, empoderamento, pretos no topo, etc.; o segundo, bem mais recente, e talvez posamos entender como uma espécie de reflexo dos desenvolvimentos do primeiro: a polêmica que ocorreu em algumas localidades, como em Goiânia, nos dias que antecederam os atos do último domingo, dia 7 de junho de 2020, entre antirracismo vs. antifascismo. Uma falsa polêmica na verdade, como aponta muito bem

${ }^{2}$ Para discussão mais detalhada, consultar os links: Disponível em: https://theintercept.com/2019/06/05/entrevistasabrina-fernandes/. Acesso em: 10 jun. 2020. Disponível em: https://www.youtube.com/watch?v=lyhADZjmJwg. Acesso em: 10 jun. 2020.

3 Disponível em: https://www.nexojornal.com.br/expresso/2018/08/01/O-que-\%C3\%A9-ser-progressistasegundo-estes-3-pesquisadores. Acesso em: 10 jun. 2020. 
Ygor Pena ${ }^{4}$, mestrando em filosofia e militante negro. Segundo ele, se deslegitima a coalizão das lutas em prol de simplesmente uma estratégia de inserção; em colaboração ao status quo, enfatiza-se identidades metafísicas. Em última instância, a ênfase nesses termos acaba por fragmentar ainda mais o que já está fragmentado, ou seja, a esquerda brasileira.

Decorre-se do que foi posto acima o primeiro ponto, já citado, que serve de partida para o presente artigo: a categoria lugar de fala. Na verdade, os limites e aporias dos usos do lugar de fala. A sistematização e definição de tal categoria mais popular vem sendo a realizada por Ribeiro (2017). Ela enfatiza, inspirada por autoras como Gayatri Chakravorty Spivak e Linda Alcoff, a necessidade da marcação do lugar para se entender realidades que foram consideradas implícitas dentro de uma normatização hegemônica. O objetivo é a diversidade de experiências para uma consequente quebra de visão universal. Nessa perspectiva, a fala não se restringe ao ato de emitir palavras, mas de poder existir. Pensa-se o lugar de fala como uma refutação a historiografia tradicional e a hierarquia de saberes advinda da hierarquia social. Muitas interpretações entendem, e a própria autora salienta, que isso não apontaria a categoria como uma questão individual, mas sim estrutural. Que não se trataria de reconhecer as vivências específicas de indivíduos como legitimadoras de todo ou qualquer discurso. Na realidade, a ideia de lugar de fala é importante quando se considera que grupos sociais passam por certas vivências comuns (mesmo quando não queiram ou as neguem), o que é relevante para a forma pela qual contribuem com a reflexão, a crítica e a construção de saberes. Lugar de fala também não serviria, por outro lado, para a imediata deslegitimação de discursos - mas sim para o reconhecimento de que eles são construídos a partir de certas realidades próprias ${ }^{5}$.

Entretanto, há autores que discordam, seja para mais ou para menos, desse entendimento do termo cunhado e de como foi disseminado por Ribeiro (2017). Douglas Rodrigues Barros, por exemplo, autor do livro "Lugar de negro, lugar de branco?", ficaria no que podemos chamar de um "meio termo" entre defesa e crítica ${ }^{6}$. Segundo sua leitura, a obra de Ribeiro (2017) pode ser separada em duas partes inerentes, mas que é melhor tratar de forma separada: lugar de fala e identitarismo. Na tentativa de dar legitimidade teórica ao conceito, a autora se foca na necessidade de resgatar a humanidade do sujeito negro via fala. O que é fundamental em um contexto de hegemonia patriarcal-capitalista, contribuindo para uma dinâmica emancipatória. Mas, Douglas aponta que a obra não deixa claro a questão sobre a necessidade de um lugar.

${ }^{4}$ Disponível em: https://terrasemamos.wordpress.com/2020/06/10/ygor-pena-o-movimento-negro-despolitizadoe-um-movimento-conservador/. Acesso em: 10 jun. 2020.

${ }^{5}$ Disponível em: https://www.e-publicacoes.uerj.br/index.php/publicum/article/view/35205. Acesso em: 10 jun. 2020.

${ }^{6}$ Disponível em: https://lavrapalavra.com/2019/03/11/lugar-de-negro-lugar-de-branco/. Acesso em: 10 jun. 2020. 
Com base em Achille Mbembe, ele aponta para a importante percepção de que a territorialização e identificação de espaços, delimitação e construção de perfis, é amplamente conivente com as formas de gestão da miséria governada pelo neoliberalismo, além de ter um aspecto policialesco inerente. A própria noção de sujeito tem sobre si determinações geopolíticas que pertencem aos exploradores da divisão internacional do trabalho, já demonstrado muito bem por Gayatri Chakravorty Spivak, em seu livro "Pode o subalterno falar?”. Assim, essa suposta necessidade do lugar interditaria a crítica. Por isso ele afirma que “a importância de sua voz é gigantesca, porém, o conteúdo que essa voz carrega, seu discurso, necessita encarnar em qualquer espaço". A necessidade de comunicar-se é fundamental, mas a fala pública é uma disputa radical. Douglas, continuando seu raciocínio, aponta que a identidade é o fracasso constitutivo da consciência na realização totalizante do Eu. Entender isso implica saber que os espaços sociais e o Outro são os responsáveis por instaurar a identificação para o controle dos corpos, hierarquização dos espaços e divisão social por meio da desigualdade fundamental para a manutenção do sistema em torno do capital. Por isso ele separa identidade do identitarismo. Esse último, segundo ele, seria o culto da violência definidora. "É o apego mítico a subordinação definidora regulada pelas relações de poder. [...] Está sempre atado a um lugar". Porém, como ele bem lembra de ser o problema, só é possível superar de fato um estado de desumanidade racializado destruindo o espaço simbólico que estruturou o mundo colonial na sua totalidade.

Já pendendo para uma visão mais crítica, seguimos aqui por uma linha diversa de interpretação ${ }^{7}$, que não exclui os méritos, mas que entende, em termos gerais que: o livro de Ribeiro (2017) não é um livro anticapitalista, mas apenas tem intuito de dar voz a quem não tem dentro do sistema; e limita-se a restituir humanidades negadas através da escuta de suas vozes silenciadas. Ele parte de pressupostos liberais-reformistas, uma fundamentação do feminismo norte-americano como um dado universal e o racismo sendo colocado como uma questão moral. Este último ponto também é abordado por Haider (2019), quando o autor aponta que a política identitária ${ }^{8}$ dividiu a esquerda. Para ele, o que pretendia ser uma estratégia

${ }^{7}$ Exemplificada e trabalhada com maior profundidade na dissertação de mestrado da autora desse artigo e também por outros autores, como pode ser visto em:

Disponível em: https://lavrapalavra.com/2018/12/05/o-lugar-de-fala-de-djamila-ribeiro-2/. Acesso em: 10 jun. 2020.

Disponível em: https://www.youtube.com/watch?v=jo7CzbtyDBs. Acesso em: 10 jun. 2020.

Disponível em: https://www.youtube.com/watch?v=tTqYPuZnwbs. Acesso em: 10 jun. 2020.

Disponível em: https://www.youtube.com/watch?v=jFzf3x8ZLX0. Acesso em: 10 jun. 2020.

Disponível em: https://www.youtube.com/watch?v=jedLb_QCXIk. Acesso em: 10 jun. 2020.

${ }^{8}$ Segundo o próprio Asad Haider: "O conceito de política identitária foi originalmente criado em 1977 pelo Coletivo Combahee River, um grupo de feministas socialistas lésbicas negras que reconheciam a necessidade de uma política autônoma própria, uma vez que se confrontavam com o racismo no movimento das mulheres, 
revolucionária para derrubar opressões entrecruzadas, acabou por tornar-se uma palavra de ordem nebulosa e cooptada pelos diferentes polos do espectro político.

Ele defende que a política identitária contemporânea é uma neutralização dos movimentos contra a opressão racial, por exemplo, e não uma progressão em relação à luta de base contra o racismo, tendo em vista que, antes as visões revolucionárias do movimento de libertação negra viam o racismo e o capitalismo como dois lados da mesma moeda, vide o partido dos Panteras Negras, mas agora foram substituídas por um conceito restrito e limitado de identidade, uma abstração. Isso ocorre, segundo Haider (2019), porque a política vem se reduzindo à performance identitária. É necessária uma retomada do "universalismo insurgente", onde os grupos oprimidos se posicionam como atores políticos, não como vítimas passivas. Se temos uma organização ou um movimento dominado por homens brancos, por exemplo, isso é um problema político e estratégico; então, se ele for tratado como um problema moral, não haverá como resolvê-lo, defende Haider (2019) ${ }^{9}$. É equivocada a crença na possibilidade de ascensão racial em um sistema que inventou as raças, que inventou um continente para dividir, controlar e usurpar suas riquezas. Tratar da questão racial é, portanto, refletir radicalmente sua fundamentação na estrutura de modernização colonial propulsora do capitalismo desde seu início. Ou seja, movimento/pautas identitário/identitárias não resume as lutas contra opressão, elas são apenas um aspecto, uma tática e se referem à vitória da classe dominante sobre a realidade de exploração e opressão.

Como muito bem colocado pelo professor Silvio Luiz de Almeida, no prefácio do livro de Haider (2019), uma política que adota a identidade como centro sem pautar um horizonte de transformação radical na estrutura social que produz as próprias identidades sociais, é correr sem sair do lugar, é um movimento que resulta em uma camisa de força, um 'looping' infinito. Disso resulta uma armadilha pois o conceito serve tanto para o que chamamos de "direita", como para uma "esquerda" de caráter antirrevolucionário. Serve a direita por que recai no individualismo, marca do liberalismo e do neoliberalismo, se tornando um fator importante para divisão e atomização social. Ao invés de romper com uma estrutura busca apenas uma melhor condição em termos materiais e de participação.

o sexismo no movimento de libertação negra, e o reducionismo de classe. Foi fundamental para sua política emancipatória trazer para o centro a forma como as opressões econômica, racial e de gênero se materializavam simultaneamente em suas vidas". (Disponível em: https://theintercept.com/2018/06/01/politica-identitaria-asadhaider/. Acesso em: 10 jun. 2020). Porém, em seu desenvolvimento, a categoria acabou se tornando uma espécie de neutralização de movimentos contra opressão. Por isso, atualmente, ela é melhor encarada como uma ideologia que apropria o legado emancipatório e o coloca a serviço do avanço das elites econômicas e política (HAIDER, 2019).

9 Também presente na entrevista: Disponível em: https://theintercept.com/2018/06/01/politica-identitaria-asadhaider/. Acesso em: 10 jun. 2020. 
Assim, o que chamamos de identitarismo afetaria a esquerda em duas linhas: 1) quando ela se recusa a falar de identidade, marca de uma esquerda 'anti-identitária', 'tradicional', que coloca a questão como desviante do plano econômico, como algo em segundo plano pois a pauta dividiria a classe trabalhadora. O problema, especialmente pensando o contexto brasileiro, é que essa classe, na sua materialidade, não é coesa, indivisa e sem contradições. Supor essa ideia é uma abstração. Logo, essa esquerda tradicional classista é igualmente identitária e antirrevolucionária como os grupos que critica. 2) Quando só se fala em identidade, a ação se limita aos limites do sistema, busca-se resolução de reivindicações na forma de direitos. Entretanto, ampliar direitos não é um problema sério dentro do capitalismo, ao contrário, tende a ajudar na sua reprodução. Quando a esquerda tem como objetivo apenas reforçar a subjetividade, as formas socais do capitalismo são preservadas. É o que Nancy Fraser chamou de "neoliberalismo de esquerda" (ou progressista). Este, é uma aliança das principais correntes de novos movimentos sociais (feminismos, antirracismo, multiculturalismo, direitos LGBTPQIA+, etc.), de um lado, e setores comerciais, simbólicos e de serviços de ponta (como o Wall Street, Silicon Valley e Hollywood), por outro. Nesta aliança, as forças progressistas estão efetivamente unidas às forças do capitalismo, especialmente à financeirização. Porém, inadvertidamente, o primeiro empresta seu carisma ao segundo. Ideais como a diversidade e o empoderamento, que poderiam, em princípio, ter objetivos diferentes, agora refletem políticas neoliberais (FRASER, 2017). Esse contexto forjou uma aliança de empreendedores, classe média, novos movimentos sociais e jovens, proclamando sua moderna e progressista boa-fé ao abraçar a diversidade, multiculturalismo e direitos das mulheres. Como apontado por Fraser (2017), o ataque à seguridade social foi encoberto por um verniz de carisma emancipatório, emprestado dos novos movimentos sociais. Ao longo dos anos, quando a indústria produzia ‘crateras' sociais, falava-se em diversidade, empoderamento e não-discriminação. Identificando progresso com meritocracia em vez de igualdade.

Mesmo com total consciência da importância de se discutir o primeiro ponto apresentado acima (efeitos sobre a esquerda), o presente artigo limita-se a propor uma discussão mais profunda sobre o segundo ponto. Por conta de limites próprio ao artigo e a pesquisa, também não traremos todo o leque de autores e discussões sobre o referido ponto. $\mathrm{O}$ foco aqui é pensar o argumento político-filosófico que está por trás da categoria 'lugar de fala', apontando o caráter de reificação, de uma postura individualista, de caráter liberal em que, muitas vezes, o uso dessa categoria recai. Para tal, usaremos, principalmente, os debates promovidos pela cientista política norte-americana Dean $(2009 ; 2016)$. 


\section{Capitalismo comunicativo}

Agora, é preciso destrinchar o contexto em que nos encontramos contemporaneamente. É o que Dean $(2009 ; 2016)$ chamará de “capitalismo comunicativo". Este, definido como sendo a materialização dos ideais de inclusão e participação nas tecnologias de informação, entretenimento e comunicação, intensificando o capitalismo global. Aqui, a Web 2.0 e suas ferramentas, a exemplo das redes sociais, fornecem a infraestrutura necessária para uma multidão que pode ver/assistir, gostar/curtir e/ou compartilhar; onde vários tipos de mensagens, inclusive de ódio, circulam facilmente (exemplo: fake news). Assim como outros espaços, essas ferramentas são regidas pela lógica do capital e pelo fetiche da mercadoria, a ênfase no consumo, no entretenimento, no marketing e na competição. No capitalismo comunicativo, as opiniões, manifestações e expressões dos mais variados aspectos se convertem à formamercadoria, onde o valor de uso contido no convencimento do outro cede espaço ao valor de troca dos "likes", números de acessos, compartilhamento, quantidade de seguidores, etc. Criase habitats discursivos específicos (online), recheados de consumismo, personalização e terapeutização, implicando em mudanças fundamentais nas condições de possibilidade de credibilidade, a exemplo do que ocorreu nas últimas eleições de 2018 para o executivo brasileiro. $\mathrm{O}$ capitalismo comunicativo baseia-se na fantasia ${ }^{10}$ da abundância que acompanha a reformatação das mensagens como contribuições e a fantasia da participação que acompanha o fetichismo tecnológico. É um contexto que tende a afastar cada vez mais a noção de "nós" (DEAN, 2009). Foca-se na performance e a alteridade desfalece; decisões coletivas, mesmo democráticas e inclusivas, cedem terreno a figuras como revolta, catarse, deserção individual e etc., ancorado na lógica de que cada pessoa só pode representar a si ${ }^{11}$.

Pensando a partir de uma realidade social marcada pela comunicação, o marketing, o consumo e, consequentemente, com reflexos no próprio psicológico dos sujeitos, Dean (2009) aponta que as mudanças políticas, econômicas e sociais das últimas décadas foram acompanhadas por ênfases crescentes no singular, individual e pessoal. Consequentemente, não se consegue fornecer boas razões para apoiar abordagens coletivas para problemas políticos, sociais e econômicos. O papel da tecnologia no momento recente, acaba por cobrir uma falta ou ausência fundamental na ordem social: protege a fantasia da unidade, dissipa uma ideia de abundância e participação. As tecnologias são investidas de esperanças, com aspirações a algo melhor. Um fetiche que nos leva a acreditar que tudo o que precisamos é ampliar, melhorar uma

${ }^{10}$ No sentido de ilusão, de uma ideia ilusória, falsa.

11 Disponível em: http://blogjunho.com.br/por-que-perdemos-moral-crista-individualismo-e-espetacularizacaonos-movimentos-de-protesto/. Acesso em: 10 jun. 2020 
tecnologia específica e então teremos uma ordem social democrática ou reconciliada. Essas fantasias dão às pessoas a sensação de que nossas ações online são significativas em termos políticos, que elas fazem a diferença. Claro, a internet tem lá a sua parcela de importância social, especialmente devido ao ainda grande alcance e influência da grande mídia (ou mídia tradicional), a autora não nega isso. Mas, destaca que os ativistas de esquerda parecem cada vez mais atraídos por eventos espetaculares e performáticos, que conscientizam, momentaneamente, mas fazem pouco no sentido de construir as instituições necessárias para sustentar uma nova ordem política. Sem falar nas dificuldades e deficiências de acesso a esses meios em determinadas regiões, pensando o contexto brasileiro.

\section{O papel do neoliberalismo}

A esquerda, em grande medida, acabou por aceitar e desfrutar os valores do neoliberalismo, celebrando as liberdades imaginárias e as transformações socioeconômicas oferecidas pela ascensão deste a partir dos anos de 1970 (DEAN, 2009; 2016). Para a autora supracitada, nos últimos anos, os estudiosos produziram análises significativas sobre o neoliberalismo visto como um conjunto de suposições políticas que favorecem as corporações, como inseparáveis da globalização e do imperialismo, como restauração de classe, como uma forma específica de governabilidade (a exemplo dos trabalhos de Michel Foucault e os de Wendy Brown) e como uma nova forma de Estado. A liberdade, em vez de justiça ou igualdade, é o valor político fundamental. O neoliberalismo atribui ao Estado um papel ativo na defesa dos mercados, na produção de sujeitos e condições para os mercados, embora não pense que o Estado deva, pelo menos idealmente, intervir nas atividades do segundo. Inevitavelmente, isso nos leva a questão da governabilidade. É aí que Dean (2009) propõem que, para os neoliberais, um dos principais objetivos da governança é construir sujeitos responsáveis cuja qualidade moral é baseada no fato de que eles racionalmente avaliam os custos e benefícios de um certo ato em oposição a outros atos. Em suma, o neoliberalismo não confia em condições preexistentes, cria novas formas, reformatando a vida social e política em termos de seu ideal de competição nos mercados. Prevalece o senso comum de que não há alternativa fora desse horizonte neoliberal. E uma das bases dessa ideologia é outra fantasia que a autora apresenta: o livre comércio.

Tal ilusão promete que um mercado sem restrições beneficia a todos. Por quê? Porque os mercados seriam as formas mais eficientes de garantir que todos façam o que lhes for mais adequado e consigam tudo o que querem. A fantasia do livre mercado é que todos vão ganhar. 
Para garantir que todos ganharão, o mercado tem que ser livre, sem restrições, liberado para realizar o seu e todo o nosso potencial (DEAN, 2009). E mais: a fantasia se manifesta em nossas práticas reais, no que as pessoas fazem no dia-a-dia. A ideologia neoliberal se concentra no comércio, isto é, nas práticas de troca. As trocas comuns de pessoas comuns, tomadas e entendidas como decisões racionais e sob condições ideais. Quando os neoliberais falam em livre comércio, a maioria de nós tende a imaginar trocas individuais (pequenos agricultores e empresas locais ou em como é bom escolher o que queremos de itens de consumo abundantes e atraentes nos supermercados e shoppings). Raramente nos focamos em bancos, cartões de crédito, hipotecas, dívidas públicas, moeda e etc. O fantástico apelo do neoliberalismo deriva, em parte, do modo como as trocas individuais substituem os fluxos globais do capital.

Outro ponto que Dean (2009) sustenta é que a fantasia responde à pergunta 'o que sou do outro?'. Nos Estados Unidos, por exemplo, a resposta do cidadão médio é 'livre', um povo livre, uma nação livre. O neoliberalismo afirma e amplia essa autocompreensão em termos de liberdade. Caminhando lado-a-lado com isso, existe a ideia de que nós (pelo menos em termos de Ocidente) somos aqueles conectados uns aos outros através da troca, e com a internet somos ainda mais livres para comprar qualquer coisa de qualquer lugar a qualquer hora. O livre comércio sustenta, no nível da fantasia, o que procura evitar no nível da realidade concreta: livre comércio entre iguais, participantes iguais com oportunidades iguais para estabelecer as regras do jogo, informações de acesso, distribuição, e assim por diante. Por um lado, esse pensamento enfatiza a necessidade de competição, ao mesmo tempo ele se apega à noção de que todos são vencedores. Noção que está em desacordo com a concorrência, porque esta é sempre marcada por vencedores e perdedores (DEAN, 2009). Para ter sucesso, o neoliberalismo depende da ocupação política organizada e da direção dos governos, do uso dos aparatos burocráticos, legais e de segurança do Estado de forma a beneficiar os interesses corporativos e financeiros. Ao mesmo tempo, para manter sua posição dominante, ele, como uma formação ideológica, tem de oferecer algo às pessoas cujas vidas molda, tem que estruturar suas expectativas e desejos para que pareça certo e permaneça tudo como está. Identidades, argumentos ou signos que são claros e convincentes, em alguns contextos adquirem pouco peso e em outros não; são limitados em seu poder e alcance, não conseguem ser completamente convincentes em uma variedade de contextos e tem repercussões diferentes para os sujeitos. Há um declínio da eficiência simbólica. O simbólico é o que conta como nossa experiência cotidiana, nossa compreensão do papel dos nomes, nossas expectativas em relação às referências, etc. Podemos dizer que o simbólico aqui se refere ao que todos aprendem. Os espaços, lógicas, práticas e normas antes reunidas em instituições sociais e econômicas 
desmoronaram e se separaram. Abriu-se espaço para subjetividades fluidas, híbridas e móveis como locais de liberdade, como se sua singularidade fosse uma propriedade natural, em vez de ela mesma imposta, inscrita e tecnologicamente gerada a serviço do capitalismo. Nesse contexto, problemas sistêmicos são tratados como os efeitos de escolhas livres, individuais, preferências e sorte. A ilusão de que o indivíduo é, e pode ser um objeto de ação (e não uma forma de fechamento e contenção), personagem central paira no ar (DEAN, 2009).

Ao longo da segunda metade do século XX, as categorias de inclusão e exclusão sociais foram politizadas e mobilizadas. Movimentos sociais organizados ao longo das linhas de raça, gênero e etnia transformaram radicalmente a vida cotidiana. Como resultado do trabalho crítico desses movimentos, bem como o consequente declínio do estado de bem-estar social e ascensão do neoliberalismo (em caráter mundial), a categoria 'nós' parece ter sido permanentemente questionada e, em seu lugar, são identidades imaginárias, fluidas, híbridas e móveis que ascenderam (DEAN, 2009), como se não houvesse uma inter-relação profunda entre esses marcadores sociais e a questão da classe. Diferentemente da identidade simbólica das instituições (o lugar a partir do qual a pessoa se vê atuando), essa identidade é a imagem que se adquire de si mesmo e se mostra extremamente vulnerável e não elimina a ênfase na responsabilidade individual. Incapaz de determinar completamente o que é certo, temos que decidir por nós mesmos. Continua-se a aliviar as corporações, instituições e o Estado das responsabilidades sociais, intensificando estas sobre os ombros dos indivíduos (DEAN, 2016). Incorporamos as fantasias da ideologia neoliberal, tornaram-se parte do ar que respiramos, elementos de nossas suposições mais fundamentais sobre como o mundo funciona: todo mundo é um indivíduo com uma identidade única.

\section{Pós-política e despolitização}

A chamada despolitização é usada como desculpa por parte significativa da esquerda para dizer que sabem que a ação coletiva é possível teoricamente, mas que não acreditam que ela exista de fato, sentencia Dean (2009): o termo marcaria a lacuna entre o compromisso com abordagens comuns para problemas sistêmicos, constitutivos do pensamento de esquerda por mais de dois séculos, e o isolamento do individualismo imerso no consumo e no capitalismo comunicativo movido pelo entretenimento. A defesa de uma despolitização significa a retirada para a covardia por parte dessa esquerda. Nas últimas décadas, teóricos políticos tentaram 
analisar a conjuntura contemporânea como pós-política ou pós-democrática ${ }^{12}$. Esses teóricos reescrevem criticamente a orientação em direção ao consenso, à administração e à tecnocracia, concebidos como benefícios do pós-Guerra Fria. A conjuntura atual seria pós-política, segundo alguns, porque a disseminação e a intensificação das políticas econômicas neoliberais sujeitaram os Estados às demandas das corporações e à lógica aparentemente inevitável do mercado. Na medida em que a autoridade do Estado é cada vez menos capaz de restringir o poder corporativo, a política também seria cada vez menos importante. Esta incapacidade da política democrática para produzir soluções viáveis para problemas sociais e econômicos ressoa com a celebração do indivíduo no capitalismo comunicativo. A individualização da política em 'estilos de vida' e opiniões, onde a política se torna respostas individualizadas a necessidades individualizadas. Com os olhos focados na sua própria performance e, portanto, desviados do espaço social onde as contradições da existência individual são coletivamente produzidas, gerando um efeito onde sujeitos são tentados a reduzir a complexidade de sua situação (DEAN, 2009; 2016).

Logo, pós-política e despolitização, entre outros termos, não seriam os mais adequados para a tarefa de teorizar esta conjuntura. Os conservadores não estão buscando respostas individualizadas, terapêuticas ou administrativas (vide exemplo de políticos conservadores brasileiros com pautas referentes a gênero). Eles querem a intervenção da lei. Eles levantam suas reivindicações para o status do universal. Eles apelam para valores de decência, moralidade, nação, unidade, ordem e civilidade como princípios universalmente válidos. E os neoliberais argumentam similarmente em termos universais. Sua alegação é que o mercado é a melhor maneira de organizar a produção, distribuição e consumo, e não que seja o melhor caminho apenas para os privilegiados e ricos. A democracia tem sido há muito tempo uma categoria contestada na política, subordinada aos direitos individuais e dos Estados, menos valorizada do que a propriedade e privilégios das elites, facilmente deixada de lado em tempos de guerra, austeridade e outros conflitos. Ao mesmo tempo, expansão das novas tecnologias de comunicação reforçou a hegemonia de uma retórica democrática, fetichizando cada vez mais a fala, a opinião e a participação. Tende-se a materializar e reaproveitar os ideais e aspirações democráticos de forma a fortalecer e apoiar o neoliberalismo. Direita e (em grande medida, no Brasil) esquerda compartilham a mesma retórica da democracia liberal, uma retórica fundindo

12 Sobre debate ver, entre outros: Disponível em:


moral e economia ${ }^{13}$, discussão e competição de modo que cada uma é uma versão da outra (DEAN, 2009).

\section{Sujeito político e redução da esquerda}

Por fim, e como já colocado em outro momento (MORAIS, 2019), todos esses apontamentos recaem no sujeito político, na agência, na ação. Aprendemos a insistir e a desfrutar da nossa diferença, a intensificar os processos de auto individuação, a celebração da singularidade pessoal. Obrigado a descobrir, decidir e expressar tudo a nós mesmos e construir a coletividade política como nostalgia das solidariedades impossíveis de um passado distante. A ideia feminista da segunda onda ${ }^{14}$ de que o 'pessoal é político' se distorceu na presunção de que o político é pessoal (DEAN, 2016). Porém, o individualismo não é essência, ele foi naturalizado e usado como meio de fragmentação de uma perspectiva coletiva. Então, quando a esquerda ecoa injunções à individualidade (presente em categorias como lugar de fala e empoderamento), quando enfatizamos perspectivas únicas e experiências pessoais (a auto verdade de uma fala mediante experiência pessoal), funcionamos como meios para a ideologia do capitalismo comunicativo. Fazendo da diferença individual a base da política, não conseguimos distinguir entre o capitalismo comunicativo e a política igualitária emancipadora. Pior ainda, fortalecemos a ideologia que impede o cultivo de coletividades politicamente poderosas. Chamar as pessoas a fundamentar suas políticas nas experiências pessoais que os diferenciam dos outros é reforçar a dinâmica de individuação. As pressões competitivas dos processos capitalistas se tornam cada vez mais deslocadas e concentradas no indivíduo. As preocupações com o eu, a autenticidade e o crescimento pessoal que se tornaram predominantes a partir da década de 1970 são sintomáticos de um individualismo que colapsa sobre si (DEAN, 2016). Aqui, vale ressaltar que "individuo" não necessariamente deve ser visto como uma só pessoa ou sujeito, mas também enquanto grupo (principalmente em termos políticos), um grupo que se comporta como indivíduo (em termos de atuação).

No final da década de 1980, a dissolução do estado de bem-estar, no norte global, o surgimento da tecnologia da informação e, mais tarde, o colapso do bloco soviético, exigiram a reconstrução da esquerda. A questão, então, era como essa esquerda reconstruída se pareceria. Um 'individualismo progressista' marcou presença e enfatizava colocar os interesses

${ }^{13}$ Cooper (2017) faz uma discussão muito interessante e maia aprofundada sobre esse tema também.

14 Para uma definição do termo e uma discussão mais ampla, ver: Disponível em: https://www.scielo.br/pdf/rsocp/v18n36/06.pdf. Acesso em: 10 jun. 2020. 
individuais no centro dessa estratégia. Para se adaptar aos novos tempos, a esquerda tem que se parecer com a direita. Esses novos tempos exigiram uma política de identidade (DEAN, 2016). Nesse contexto, tal política deve estar no centro de uma política transformadora, porque dá uma sensação de diferença, das muitas identidades oferecidas na e pela cultura contemporânea. A fragmentação da política de esquerda em uma matriz cada vez maior, populista, liberal, progressista, verde, multiculturalista, antirracista, democrática radical, feminista, identitária, anarquista, queer, autonomista, horizontalista, anti-imperialista, insurrecionista, as convicções libertárias, socialistas e comunistas, etc., são sintomáticas e recheiam discussões entre ativistas e acadêmicos.

Nessa lógica, a premissa é de que a coletividade é indesejável e impossível (DEAN, 2016). A coletividade é indesejável porque se suspeita de excluir possibilidades, apagar a diferença e impor a disciplina. No lugar dessa coletividade, o suposto realismo de parte da esquerda oferece diversidade, pluralidade e multiplicidade. Tais pontos de vista procedem como se essa multiplicidade fosse primariamente ontológica, ao invés de também estimulada pelo capitalismo. Segundo Dean $(2009 ; 2016)$, isso levou teóricos e ativistas de boa parte da esquerda, que criticam grandes e más corporações e os extremos crescentes entre riqueza e pobreza, a acharem extraordinariamente difícil pensar em alternativas para a atual configuração de poder. Em parte, isso ocorreria porque não conseguimos dar voz a valores de coletividade, cooperação, solidariedade e equidade suficientemente fortes para combater a fantasia de livre comércio do neoliberalismo. Por mais que muitos defendam as afirmações da diferença, singularidade e fluidez de modos de ser como posturas radicais, como uma espécie de vanguarda, é perigoso ignorar a relação disso com o neoliberalismo, o impulso que este dá a diversidade. É bom ser diferente e a direita também apoia isso. Aqui existe um jogo de disputas ideológicas. Quando o inimigo de alguém aceita os termos de uma pessoa, o ponto de crítica e resistência é perdido, a dimensão do antagonismo desaparece. Outros conflitos menores emergem, tornam-se locais que atraem e sugam as energias políticas (DEAN, 2009). Tal visão de Dean (2009; 2016) é corroborada, por exemplo, por Haider (2019). Segundo este último, a política identitária contemporânea é uma neutralização dos movimentos contra a opressão, e não uma progressão em relação à luta de base contra esta. Ele argumenta que a identidade foi abstraída das nossas relações materiais com o Estado e a sociedade. Assim, quando a identidade serve de base para as crenças políticas de alguém, ela se manifesta em divisionismo e atitudes moralizantes, em vez de estimular a solidariedade. 


\section{Implicações políticas}

Os conflitos em torno da identidade acabam por gerar questões difíceis: seria necessário transformar a estrutura econômica do capitalismo contemporâneo no intuito de compensar os passivos econômicos desses grupos oprimidos? O que exatamente significa a 'estrutura econômica'? Deve-se conceber a regulação heteronormativa da sexualidade como pertencente diretamente à economia capitalista? Ou é melhor visto como pertencente a uma ordem de status que é diferenciada e complexamente relacionada à estrutura econômica? As relações de reconhecimento na sociedade neoliberal coincidem com as relações econômicas? As diferenciações institucionais do capitalismo moderno introduzem lacunas entre status e classe?

Para pensar tais questões é importante, por exemplo, voltarmos a visão socialistafeminista dos anos 1970, onde a família faz parte do modo de produção para apoiar a tese de que a regulação heteronormativa da sexualidade é central no funcionamento da economia política (COOPPER, 2017). A estrutura econômica é todo o conjunto de mecanismos e instituições sociais que (re)produzem pessoas e bens. Por definição, então, a família faz parte dessa estrutura, como o principal local para a reprodução e o cuidado de pessoas. Por extensão, é a ordem de gênero que padroniza os 'produtos' da família para se adequarem a dois tipos de pessoas aparentemente naturais, mutuamente excludentes: homens e mulheres. A ordem de gênero, por sua vez, sustenta-se para pressupor um modo de regulação sexual que produz e naturaliza a heterossexualidade. Essa é uma especificidade da sociedade capitalista como uma forma distinta e altamente peculiar de organização social. Essa organização cria uma ordem de relações econômicas especializadas que são colocadas como dissociadas das relações de parentesco, quando na verdade, não o são. Não é de admirar, portanto, que os principais oponentes dos direitos de gays e lésbicas hoje, por exemplo, não sejam corporações multinacionais, mas conservadores religiosos. Na verdade, algumas multinacionais provocaram a ira de tais conservadores ao adotarem políticas amigáveis a comunidade LGBTQ+ (FRASER, 2013), como foi o caso do Banco do Brasil e do Boticário ${ }^{15}$ recentemente aqui no Brasil. Isso levaria a crença de que não é necessário derrubar o capitalismo para remediar essas deficiências, mas precisamos transformar a ordem de status existente e reestruturar as relações de reconhecimento, naquela velha lógica reformista de algumas vertentes da esquerda ${ }^{16}$.

Essa perspectiva leva Fraser (2013b) à máxima de que, por exemplo, alguns feminismos se tornaram servos do capitalismo, ou seja, um movimento que começou como uma crítica da

${ }^{15}$ Disponível em: https://www.youtube.com/watch?v=p4b8BMnolDI. Acesso em: 10 jun. 2020.

${ }^{16}$ Exemplo dessa discussão é o livro de Rosa Luxemburgo "Reforma ou revolução". 
exploração capitalista acabou contribuindo com ideias-chaves para a sua mais recente fase neoliberal, fornecendo a justificativa para novas formas de desigualdade e exploração. Contra todas as expectativas, aparentemente alguns movimentos pela libertação das mulheres adquiriu ligação altamente perigosa com os esforços neoliberais de construir uma sociedade de livre mercado. Fato que nos ajudaria a entender como algumas ideias feministas que antes faziam parte de uma cosmovisão radical são cada vez mais expressas em termos individualistas (ex.: mulheres empreendedoras). Segundo Fraser (2013b), o que estaria por trás dessa mudança, que reverbera diretamente nas questões abordadas aqui sobre lugar de fala, é uma mudança radical no caráter do capitalismo. O capitalismo estatal da era pós-guerra deu lugar a uma nova forma de capitalismo: globalizante, neoliberal, como vimos acima. O feminismo da segunda onda surgiu como uma crítica do primeiro, mas tornou-se servo do segundo. Para a autora, o movimento pela libertação das mulheres apontou simultaneamente para dois futuros possíveis diferentes. O primeiro, prefigurou um mundo em que a emancipação de gênero andava de mãos dadas com a democracia participativa e a solidariedade social; o segundo cenário, prometia uma nova forma de liberalismo, capaz de garantir às mulheres e aos homens os bens da autonomia individual, o aumento da escolha e o avanço meritocrático. O feminismo da segunda onda era nesse sentido ambivalente, compatível com qualquer uma das duas visões diferentes da sociedade. Mas, tal ambivalência foi resolvida nos últimos anos optando em favor do segundo cenário: um liberal-individualismo.

\section{Considerações finais: lugar de fala como um individualismo por via oblíqua}

Partindo das premissas de que: 1) muito daquilo que se passa por novidade na política radical atualmente encerra uma reprodução de lógicas de ação que não se separam do status quo liberal; e 2) os movimentos/pautas identitários/identitárias são uma tática na luta contra as opressões, mas vem se tornando uma ideologia que apropria o legado emancipatório e o coloca a serviço do avanço das elites econômicas e políticas; chegamos aos apontamentos abaixo.

Os movimentos de esquerda tiveram importantes vitórias, em termos culturais e políticos, no pós 1968 e durante as décadas de 1980 e 1990, mas o entusiasmo pela diversidade, pela multiplicidade e pela agência de consumidores que ativamente transformam seus estilos de vida acabou, segundo autoras tão diversas como Nancy Fraser e Jodi Dean, unindo grande parte da esquerda e o capital. A política identitária, representada aqui pelo uso do lugar de fala nos grupos de militância, vem se mostrando um individualismo por via oblíqua e com uma tendência perigosa a deslocar o eixo da política de esquerda, da coletividade para o indivíduo. 
Apresentamos a existência de uma extrema valorização do ato de dizer, as vezes mais do que o conteúdo do que se diz e como isso reverbera na dinâmica política (a auto verdade). Em um contexto de capitalismo comunicativo, tende-se a afastar cada vez mais a noção de um "nós". O problema político real é que uma parcela grande do que entendemos como esquerda passou a aceitar o capitalismo e a democracia liberal como seu horizonte último, se esquecendo de que a injunção do capitalismo para individualizar é a sua arma mais poderosa, pois dificulta que as pessoas se unam em torno de uma luta comum. Vivemos em uma época em que se sobrecarrega o indivíduo de responsabilidades e expectativas e onde a coletividade é indesejável porque supostamente exclui possibilidades, apaga a diferença. Nossos apontamentos ao longo do texto se encontram em paralelo com a defesa de Haider (2018) da política identitária ter dividido a esquerda. Assim, temos como resultado: categorias como lugar de fala que, se levadas ao limite, se tornam um cemitério para a alteridade, a impossibilidade da solidariedade, assentando o primado da experiência pura sobre a interlocução. A fragmentação da esquerda se reduz às individualidades e suas singulares experiências. Em última instância, nada mais conservador do que a redução da humanidade à promoção da dor como licença moral e a exaltação da experiência individual como argumento político revestido de validade intrínseca ${ }^{17}$. Ou seja, além de fragmentar ainda mais a esquerda, dificultar a formação de coletividades para a luta política frente as estruturas de opressão e exploração (necessariamente interconectadas), o que chamamos de política identitária também é, por incrível que pareça, conservadora.

AGRADECIMENTOS: ao professor Franck Tavares (Faculdade de Ciências Sociais/ Universidade Federal de Goiás), pela paciência e dedicação no processo de orientação que deu origem a este texto.

\section{REFERÊNCIAS}

COOPPER, M. Family values: between neoliberalism and the new social conservatism. New York: Zone Books, 2017.

DEAN, J. Democracy and other neoliberal fantasies: comunicative capitalism and left politics. Duke University Press: Durham \& London, 2009.

DEAN, J. Nothing personal. In: DEAN, J. Crowds and party. London, UK: Verso, 2016. p. $25-49$.

17 Disponível em: http://blogjunho.com.br/por-que-perdemos-moral-crista-individualismo-e-espetacularizacaonos-movimentos-de-protesto/. Acesso em: 10 jun. 2020. 
FRASER, N. Fortunes of feminism: from state-managed capitalism to neoliberal crisis. London, UK: Verso, 2013.

FRASER, N. How feminism became capitalism's handmaiden: and how to reclaim it. The Guardian, 14 out. 2013b. Disponível em:

https://www.theguardian.com/commentisfree/2013/oct/14/feminism-capitalist-handmaidenneoliberal. Acesso em: 3 ago. 2018.

FRASER, N. The end of progressive neoliberalismo. Dissent Magazine, 2 jan. 2017. Disponível em: https://www.dissentmagazine.org/online_articles/progressive-neoliberalismreactionary-populism-nancy-fraser. Acesso em: 01 ago. 2018.

HAIDER, A. Armadilha da identidade: raça e classe nos dias de hoje. Trad. Leo Vinicius Liberato. Prefácio de Silvio Almeida. São Paulo: Veneta, 2019.

MORAIS, L. B. V. Implicações da política identitária na práxis da Esquerda. In:

Justificando: mentes inquietas pensam Direito, 5 dez. 2019. Disponível em:

https://www.justificando.com/2019/12/05/implicacoes-da-politica-identitaria-na-praxis-daesquerda/. Acesso em: 27 jun. 2020.

RIBEIRO, D. O que é: lugar de fala? Belo Horizonte, MG: Letramento, Justificando, 2017.

\section{Como referenciar este artigo}

MORAIS, L. B. V. Lugar de fala, política identária e seus reflexos na práxis da esquerda. Rev. Sem Aspas, Araraquara, v. 9, n. 1, p. 80-96, jan./jun., 2020. e-ISSN: 2358-4238. DOI: https://doi.org/10.29373/sas.v9i1.13939

Submetido em: 10/07/2020

Revisões requeridas: $15 / 08 / 2020$

Aprovado em: 05/09/2020

Publicado em: 30/09/2020 